\title{
Family Development in the Face of Cancer
}

\author{
Karen Weins and Mary Politi
}

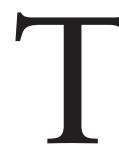
he National Cancer Institute reported that 8.9 million Americans who have had cancer were alive in 1999 (American Cancer Society, 2003). The number of cancer cases has increased while the incidence of cancer mortality has declined from 1973 to 1999 (Edwards et al., 2002). As a result, patients and families must learn to live with the chronic physical and psychosocial adjustments of a cancer diagnosis.

The majority of families mount a resilient response over time, despite the suffering that is universal for those living with cancer (Arpin, Fitch, Browne, \& Corey, 1990; Grassi \& Rosti, 1996; Skerrett, 1998). They report feeling closer to one another after marshaling resources to fight the disease (Lewis, Woods, Hough, \& Bensley, 1989; Skerrett, 1998). Although many families report this positive response, the physical and emotional pressures during the different stages of cancer can strain family relationships, even among families who cope well with the diagnosis and its effects (Carlson, Bultz, Speca, \& St.-Pierre, 2000; Halford, Scott, \& Smythe, 2000; Veach \& Nicholas, 1998).
Furthermore, some families of cancer patients express psychological distress as much as, if not more than, the patients (Ferrell, Ervin, Smith, Marek, \& Melancon, 2002; Northouse, Mood, Templin, Mellon, \& George, 2000; Omne-Ponten, Holmberg, Bergstrom, Sjoden, \& Burns, 1993). Researchers have reported that one third to one half of cancer patients meet the diagnostic criteria for a wide range of disorders, including adjustment disorders, affective disorders, and anxiety disorders (Derogatis et al., 1983; Grassi \& Rosti, 1996). In addition to the direct effects of cancer on families, these negative psychological changes in the patient can influence the quality of the family environment and family adjustment to cancer (Baider, Koch, Esacson, \& Kaplan-DeNour, 1998; Ben-Zur, 2001; Omne-Ponten et al., 1993), resulting in decreased closeness in family relationships (Ell, Nishimoto, Morvay, Mantell, \& Hamovitch, 1989).

Family environments can affect the level of the patient's and family members' distress. Cohesive family environments with low conflict include family members 
who are less distressed and have better coping than patients, partners, and children whose families are detached or high in conflict or both (Arpin et al., 1990; Bloom, Pendergrass, \& Burnell, 1984; Lewis et al., 1989). Some research has shown that high emotional expressiveness and cohesion in family relationships predict better psychological adjustment to cancer in all family members (Giese-Davis, Hermanson, Koopman, Weibel, \& Spiegel, 2000; Kayser, Sormanti, \& Strainchamps, 1999; Trask et al., 2003). Other studies have demonstrated that spouses' avoidance and criticism can lead to patients' sense of diminished attractiveness or self-worth, suppression of emotions, anxiety, or depressed mood in response to cancer (Manne, 1999), and that perception of spouses' emotion-focused coping, such as inconsolable worry or avoidance, can increase both patients' and spouses' distress (Ben-Zur, 2001). When young children have cancer, maternal distress may have an impact on the later psychological adjustment of the children (Sawyer, Streiner, Antoniou, Toogood, \& Rice, 1998). These findings highlight the major impact of family functioning on adjustment to cancer.

Another intriguing body of knowledge involves the prediction of higher rates of disease progression and death for cancer patients based on poorer social and familial relationships (Levy, Herberman, Lippman, D’Angelo, \& Lee, 1991; Reynolds et al., 1994; WaxlerMorrison, Hislop, Mears, \& Kan, 1991). These researchers show that some attributes of the family, such as low nonhousehold support (Weihs, 2001; Ell, Nishimoto, Mediansky, Mantell, \& Hamovitch, 1992) or a hostile marital or partner relationship (Weihs, Enright, \& Simmens, 2002), may adversely influence the course of the biologic disease process, although it is not clear whether the latter attributes are the same as those that correlate with psychosocial adjustment.
In this chapter, we discuss the impact of cancer on the family system during this threat to the family life cycle. We use theories of family development and attachment to organize information from published reports and studies as well as from our own research and clinical experience.

\section{CANCER AS A THREAT TO THE LIFE COURSE OF THE FAMILY}

Cancer threatens to separate the patient from his or her family members, both emotionally and physically. Such threats can seriously divert the life course of the family. The life course of the family is manifest in its continuity over time. It arises from its particular history and is guided toward the future by shared values and goals including the maintenance of health, personal development, productivity in education and in work, recreation, community involvement, and preservation of family integrity.

Our concept of threat is informed by the work of Brown and Harris (1989), who based their assessment of the magnitude of threat on the meaning of life events in the context of close relationships, personal history, and social circumstances. The meaning of a threatening situation is based on the values, plans, and goals of the family (Weber, 1947/1964). The assessment of threat in psychooncology is therefore likely to be a useful way to bring together the tangible facts about the cancer experience and their human context to study their effects on the family over time.

\section{ATTACHMENT PROCESSES AND ADJUSTMENT TO CANCER}

To understand the family's response to the cancer threat, we examined studies of human development that explain individual differences in responding to distress and separation 
among family members. Bowlby (1969) described such a behavioral, motivational system as the attachment system. There are three distinguishing features of the attachment system that are helpful in understanding its operation. First, the attachment behavioral system may or may not be active at any given time. Second, attachment is manifested in, but not defined by, a limited set of characteristics that arise when access to the attachment figure exceeds some individually defined limit. These characteristics include crying out or moving close to the person in whose presence one feels more secure. Children may become "clingy," and spouses may become overprotective. Finally, internal working models of family relationships are cognitive mental schemas based on prior attachment experiences, including changes in attachment relationships after cancer in prior generations or earlier in life, current interactions between the person and family member when the attachment behavioral system is activated, or both (Berman \& Sperling, 1994).

Attachment processes operate throughout the life cycle, beginning with their influence on infant behavior during times of danger or threatened separation from the primary caretaker. Expressing distress and seeking closeness to a significant other triggers the complementary "caregiving response" in the person with whom an attachment relationship had been previously established. Ainsworth and colleagues (Ainsworth, Blehar, Waters, \& Wall, 1978) developed an experimental procedure called the strange situation, which enabled the documentation of children's differences in the use of their parents for calming. Observations of reunion behavior after an experimental separation were used to classify differences in both the infant and the parental behavior. Children with a secure attachment were found to greet the returning parent with open arms. The parents of these children then responded promptly and appropriately so that the infant was easily calmed. Those children with an insecure attachment, however, displayed three types of behavior. Some displayed an "avoidant" style by keeping away from their mothers at the reunion, which prompted the mothers to provide less affectionate holding. Others maintained an "ambivalent" response by acting clingy and remaining distressed, which was a response to inconsistent sensitivity by their mothers. A third group of insecure infants identified later by Main and Hesse (1990) showed a "disorganized" pattern of responding. These infants were both avoidant and resistant, demonstrating more disorganized behaviors. Throughout the lifetime, these attachment and caregiving responses are mutually reinforced reciprocal patterns in an attachment relationship (Hinde, 1982), which has enduring and irreplaceable bonds (Bowlby, 1969, 1988).

Differences in individual attachment style develop out of attachment experiences in each person's life. They form the basis for the unfolding of family relational processes, which are highly relevant to psychological adjustment to many life events, including cancer. Wynne (1988) applied the findings related to attachment researchers in his epigenetic model of enduring family relational systems. His model informs our understanding of changes in family relationships in response to the cancer experience.

Wynne expanded on Bowlby's observations of a developmental hierarchy of capacities within the individual to describe development within relationships. He describes change in family systems as epigenetic. Epigenesis (Singer \& Wynne, 1965) refers to

events of becoming (genesis) [italics added] that build upon (epi) [italics added] the immediate preceding events. Constitutional and experiential influences recombine in each phase to create new potentialities. This determines the next phase. If the transactions at any given phase are distorted or omitted, all the subsequent phases will be altered because they build upon a different substrate. (p. 208) 
We would then predict that activation of attachment relational processes in response to cancer would trigger an epigenetic sequence of development in family relational capacities. If secure attachments are activated and reinforced through sensitive responsiveness of family members to the cancer distress, then revisions of other relational capacities are likely to occur without distortion or impasse. Attachment relational processes, in Wynne's epigenetic model, are the substrate from which other family processes are developed (Wynne, 1988). Four capacities for relating within the family that arise in the epigenetic process are attachment/caregiving, communication, joint problem solving, and mutuality. Each process can be thought of as the positive side of a domain, which also has its converse. For example, separation is the converse of attachment; optimal relationship function includes fluctuations between separation and attachment behaviors. Through recursive, "circular" processes, each level of relational process influences adjacent levels. For instance, the quality of communicating shapes the security of attachment within relationships.

Communication is characterized as optimal when there is shared focusing of attention and a belief in a shared social reality. If this communicative sharing is not accomplished, then the security of attachment will not be reinforced, and eventually it will deteriorate to some derivative of insecurity or the relationship will be abolished. Families in which a member has cancer need to communicate their individual experiences of threat so that a shared understanding of needs and appropriateness of attachment and caregiving behaviors can occur.

Joint problem solving involves shared engagement in tasks that create the potential for relational growth (Wynne, 1970). Over time, roles develop as a result of the repetition of task-related transactions to accomplish tasks. Joint problem solving has been described as the bridge between relational processes and family structures, such as roles. For example, when a woman has cancer, her role often needs to shift dramatically during cancer treatment from predominantly caregiving for others to seeking care for herself. New problem-solving strategies are needed when a parent with cancer is unable to carry out his or her usual activities, such as driving children to after-school events, house cleaning, or planning a vacation.

Mutuality is the "flexible, adaptive pattern of relational continuity that incorporates change" (Wynne \& Wynne, 1986, p. 385). Mutuality incorporates both distancing or disengagement and constructive reengagement as new circumstances make old ways of communicating and problem solving ineffective. A family that is able to relate with mutuality maintains its composition of membership but changes the roles that its members take in response to a new situation.

Cancer requires the family to revise its ways of relating; therefore, mutuality is a crucial determinant of the threat to the family life course from cancer. Problems related to cancer care require family members to shift roles, which must be mutually determined by the people involved. If common ground is not created, the relationship is at risk for rupture or for the development of pseudomutuality, when family composition is maintained but a secure and responsive base for relating has been lost.

Our observations of differences in family patterns of engagement, when cancer threatens to separate them from the patient, are consistent with the differences in attachment based on family relational processes described previously.

\section{FAMILY RELATIONAL PROCESSES BASED ON ATTACHMENT}

We use the word family to designate a group of individuals with close personal relationships whose identities develop in conjunction 
with one another over time. The family affects the lives of its members through the patterning and quality of relatedness more than through the number of members or its formal designations (marriage, family, intimate partnership, etc.). This definition allows us to use a common approach to "families" with varying compositions of individuals and across different cultural and ethnic groups.

Cancer threatens to separate the patient from his or her family members, both emotionally and physically. Family relational processes modulate the impact of the cancerrelated threat on the life course of the family. Secure family relationships protect the family from the destructive impact of stressful life events on the psychological adjustment of family members and on the family life course. Conger and colleagues (Conger, Ge, Elder, Lorenz, \& Simons, 1994; Conger, Patterson, \& Ge, 1995) demonstrated that the effects of external stress on individual family members are mediated through changes in family relationships. They studied 225 Iowa families facing severe economic threat and found increased marital conflict and parental depression in some families. The same families were visited 1 year after the first contact. Increased marital conflict, documented in the previous year, predicted hostility in the parent-child relationship and depression and antisocial behavior in adolescents. A direct effect of economic stress on the outcomes of the children was not detected, supporting the notion that changes in the security of familial relationships mediate destructive effects of economic threat on adolescent psychological adjustment (Whitbeck et al., 1991). The cancer threat can act in a similar manner, with changes in relationships affecting the psychological adjustment of family members more than the cancer.

Insecure relationships are especially vulnerable to the destructive effects of threats. Individuals with insecure working models of attachment are most at risk for prolonged distress from cancer, which is not assuaged by nonhousehold social support. The uniqueness of the cancer experience leaves patients feeling as if no one understands their terror and alienation (Bahnson, 1975). A person with insecure working models of attachment relationships may expect misunderstanding, criticism, rejection, burdensome care seeking from others, or all of these in response to his or her disclosure of distress about cancer treatments or fear of death (Levitt, Coffman, Guacci-Franco, \& Loveless, 1994). He or she would therefore limit self-disclosure and requests for support (Mikulincer \& Nachshon, 1991; Simpson, Rholes, \& Nelligan, 1992). Such behavior may take the form of repressive coping, in which individuals minimize their distress in an attempt to conform to make other family members more comfortable or to appear more "normal." Repressive coping is thought to be a risk factor for more rapid disease progression by some investigators (Temoshok, 1985; Weihs, Enright, Simmens, \& Reiss, 2000; Weinberger, 1990). It may also be expressed as depressed mood, irritability, and decreased social functioning.

A "cancer legacy" from the past may introduce distortions in otherwise secure family relationships. Cancer-related losses of relationships or painful, maladaptive interchanges during the illness of loved ones in the past may increase the sense of danger from cancer to the family (Rolland, 1994). Patients who fear that they will be a burden to their family may avoid disclosure of distress and thereby foreclose opportunities for comforting responses. Such withholding can signal family members to separate themselves from the patient, creating an avoidant pattern of relating with decreased communication about the cancer and decreased availability of joint problem solving for addressing the treatment needs of the patient.

Alternatively, increased security may develop in a family when such cancer legacies 
are revised during a new episode of cancer. When sensitive supportive responding is used to calm the distress of members threatened with separation or loss, a new and deeper sense of closeness and security may occur. In this way, the cancer experience is an opportunity for some families to revise the cancer legacy, feeling more secure in their ability to care for one another and actively manage the cancer treatment and its effects.

\section{The Impact of Cancer on Family Relationships Varies with Security of Attachment}

The threat of cancer to the family can best be estimated by understanding the personal and social contexts. Veach and Nicholas (1998) discussed the clinical course of cancer and its relation to three stages of family development: the newly forming family, the young family, and the aging family. The newly forming family consists of a married couple with no children struggling to become independent from their families of origins (Veach $\&$ Nicholas, 1998). The threat of cancer may challenge the new family bonds the couple has formed. In the absence of a secure attachment relationship, a partner might show emotional over-involvement, emotional withdrawal, or hostility toward the cancer patient. This response might lead one or both partners to turn to a more stable family setting, perhaps each partner's family of origin (Veach \& Nicholas, 1998). Researchers have shown that newer couples experience more stress than older couples as a result of cancer diagnosis (O’Mahoney \& Carroll, 1997; Skerrett, 1998).

The young family, consisting of a married couple with young children, often has the most difficulty coping with the threat of cancer (O'Mahoney \& Carroll, 1997; Veach \& Nicholas, 1998). Members of young families are focused on establishing stability and roles for each other. With the threat of cancer, children often assume parental roles, and the parent-child relationships and boundaries are disrupted temporarily. During adolescence, the gradual development of familial responsibilities is crucial to maintaining a solid family environment as adolescents struggle between wanting more independence from their parents and still looking to them for support and reassurance. Thus, changes in relationships as a result of a threat can particularly affect the psychological adjustment of adolescents (Spira \& Kenemore, 2000; Lewis, 1996). The quality of adolescent peer relationships can decline, their self-esteem can suffer, and their behavior problems can increase as more illnessrelated demands are placed on the family (Lewis, 1996).

Furthermore, children might feel guilt about their parent's diagnosis or internal conflict about caring for their parent while maintaining their own interests or both (Veach, 1999). Parents might struggle with deciding on appropriate information to share with their younger children (Sherman \& Simonton, 2001), finding external resources to help with transportation and household duties relating to their children (Veach, 1999), and worrying about whether they will be able to parent their children through adulthood (Skerrett, 1998). These struggles are more difficult among families with trouble communicating or poor problem solving or both.

Finally, the aging family, consisting of an older patient with grown children, must cope with its own unique set of stressors. Grown children might not live in the patient's household or even in a nearby geographic location, and caretaking is often more difficult in the absence of some family members (O’Mahoney \& Carroll, 1997; Veach, 1999). Older couples managing cancer are often at risk for relational, psychological, and health-related distress (Shields, Travis, \& Rousseau, 2000). Since the 
caregiving response more naturally occurs among those who are securely attached (Hinde, 1982), these challenges are likely to be exacerbated in families with insecure patterns of attachment.

When a child has cancer, families must cope with maintaining family function despite disruption of their routines, much like when an adult has cancer. However, parents often try to mask their distress because they fear upsetting the sick child or because they feel guilty about the child's illness (Sawyer et al., 1998). When parents do not adequately cope with their distress, they can negatively affect the psychological adjustment of the child (Sawyer et al., 1998). As with families of adult patients, the family's use of appropriate communication about cancer, although difficult for many parents, can aid in the family's adjustment to cancer diagnosis in children (Sherman \& Simonton, 2001).

\section{The Impact on Family Relationships Varies with Clinical Course of Cancer}

The clinical course of cancer affects the threat that families encounter (Rolland, 1994; Suinn \& VandenBos, 1999). Each phase of the illness presents the possibility of revision in attachment style within the family and thereby the substrate for resilience or vulnerability to destructive changes in life course in response to cancer.

Researchers often discuss four phases of cancer: initial diagnosis, treatment, recovery and survival, and disease progression and recurrence (Sherman \& Simonton, 2001; Veach, 1999; Veach \& Nicholas, 1998). During the initial diagnosis of cancer, patients and family members often feel shock, anxiety, confusion, and fear about the uncertainty of the illness (Halford et al., 2000; Sherman \& Simonton, 2001; Veach \& Nicholas, 1998). Some refer to these issues as the "existential plight" of cancer (Weisman \& Worden, 1976), which takes place during the first 100 days after cancer diagnosis. During this time, families must deal with the sudden vulnerability of one of their members while also changing roles and priorities within the family structure to accommodate their new uncertainty. Some researchers have found that wives of cancer patients are often more distressed than the patients during the initial diagnosis phase, possibly because they often take on the burden of caregiving (Carlson et al., 2000).

During the second phase of cancer, the treatment phase, families must cope with the decision making about biomedical treatment, frequent medical appointments, treatment side effects (fatigue, hair loss, nausea, and pain), and further disruption in the family routine (Halford et al., 2000; O'Mahoney \& Carroll, 1997; Sherman \& Simonton, 2001; Veach \& Nicholas, 1998). The side effects of treatment can also lead to sexual difficulties for couples (Halford et al., 2000; O’Mahoney \& Carroll, 1997). The financial stress resulting from medical expenses and time off from work for both the patient and the spouse can increase distress in both parents and children (Sherman \& Simonton, 2001). Despite these changes, many also feel relieved and empowered during this phase because of the active response taken to fight the disease (Sherman \& Simonton, 2001; Veach \& Nicholas, 1998).

The third phase of cancer has been described as the recovery and survival phase. Patients are no longer undergoing active treatment for their cancer, leaving some families feeling vulnerable and passive upon resuming daily routines (Veach \& Nicholas, 1998). Many patients and family members feel a sense of uncertainty about the future and a fear of recurrence, causing them to reevaluate their roles, goals, priorities, or spiritual values or all of these (Halford et al., 2000; Sherman \& Simonton, 2001). 
Unfortunately, many of the psychological and physical effects of cancer can persist for several years (Halford et al., 2000), but patients and families are often left with weaker support because others may not recognize these lingering effects. Conflicts can arise between family members who wish to leave the experience behind them and those who are still struggling with the disease effects (Sherman \& Simonton, 2001). The life course of the family may also be challenged during this phase with fewer external resources to help cope with the threat of cancer recurrence.

If the cancer recurs, spouses, especially husbands, experience extreme distress because they must deal with the possibility of losing their partner (Carlson et al., 2000). Existential and spiritual issues often reemerge in the family as the patient often undergoes more aggressive medical treatment (Sherman \& Simonton, 2001). During this phase, the unpredictability of the illness again challenges the ongoing security of the family to defend its vital functions against the cancer intruder. Death and premature resolution of their life course is the final phase of the cancer experience for many patients and their families.

Silberfarb, Mauer, and Crouthamel (1980) report the phase of disease recurrence to be the most distressing for patients and families. Security in family relationships is crucial at later stages of disease when the family may already be severely taxed by the illness experience. If security in the family is low during remission of the cancer, the family could face recurrent disease without the ability to function together. Preservation and restoration of family function during each phase of illness are needed to prevent the deterioration of relationships as the disease progresses. This can be achieved through effective communication and attention to each family member's needs during the different phases of the illness. During the recurrence phase, issues of identity, existential meaning, preserving quality of life, sustaining the caregivers, and confronting mortality should be addressed within the family or with a trained professional to help strengthen family function (Sherman \& Simonton, 2001).

\section{CANCER AND MARITAL RELATIONSHIPS}

Marital status has been studied extensively as a predictor of cancer outcome. Results remain inconsistent, however. Some studies combining men and women show a survival advantage to being married (House, Robbins, \& Metzner, 1982; Kravdel, 2001; Ren, 1997), whereas others have failed to find such effects (Murphy, Goldblatt, Thornton-Jones, \& Silcocks, 1990; Neale, 1994). Studies of women with breast cancer often show no effect or negative effects of marriage on length of life (Forsen, 1991). Two separate studies reported an advantage in survival time for unmarried women with breast cancer compared to those who are married (Ell et al., 1992; Waxler-Morrison et al., 1991). It is possible that the type of cancer, the patient's gender, the racial background of the couple, or all three may explain some of the conflicting results (Kravdel, 2001; Zhu, Weiss, Schwartz, \& Daling, 1994).

Marital quality has not been studied extensively as a prognostic factor for disease outcome in cancer patients, but there is evidence that the quality of the marital relationship can influence disease recovery (Burman \& Margolin, 1992). Research by Weihs and Enright (2003) found that women who confide in their spouses during times of stress have a better prognosis for survival from breast cancer. In addition to physical health benefits, higher marital quality can decrease the level of patient distress in response to cancer and can lead to fewer illness-specific 
adjustment problems (Rodrigue \& Park, 1996). Kayser and colleagues (1999) demonstrated that women with breast cancer who reported highly mutual partner relationships had better quality of life ratings and less depression than women whose partner relationships were not perceived as highly mutual. In the same group of women, symptoms of cancer, length of illness, and socioeconomic status did not have a strong effect on the women's psychosocial adaptation. Giese-Davis and colleagues (2000) found similar results in their study of marital status and relationship quality among metastatic breast cancer patients and their partners. They found that relationship quality and distress of the patient's partner were associated with the patient's mood, whereas indices of disease status were not, further demonstrating the significance of the marital relationship as the mediator of the effects of cancer on psychological functioning.

\section{CASE EXAMPLES}

Families in which insecure attachment patterns predominate would be expected to exhibit distortions such as overinvolvement, avoidance, or criticism in response to expressions of distress about cancer. Wynne's model suggests that subsequent dysfunctions of communication, problem solving, and mutuality would also occur in these families. Insecure relational processes fail to provide a "holding environment" in which the distress associated with cancer can be shared and relieved for some or all family members. The distressed person does not receive a comforting and accepting response. Others might become distressed and focused on their own strong feelings (emotional overinvolvement), they might withdraw from the distressed person ("flat" detachment), or they might become controlling or hostile toward the person expressing distress. These responses do not promote security in the relationship. Whether they transform the meaning of the previous relationship depends on the meaning of the exchange to the family members involved.

There are many proposed strategies to help patients and family members cope with the disruption of cancer in their lives, particularly those struggling with insecure relational processes. Some strategies, such as support groups or family therapy or both, can help strengthen relationships by fostering communication and emotional expression in families. Normalizing the disruptive effect of cancer on family life is an essential component of these psychological interventions (Gonzalez, Steinglass, \& Reiss, 1989). Furthermore, clinicians working with families with young children might want to ask the children to express their feelings through drawings or other nonverbal forms of communication. Clinicians can encourage the older family members to discuss the drawings with the children to help include even young family members in the illness experience (Sherman \& Simonton, 2001).

In addition to enhancing family communication, during the early phases of cancer, some researchers and clinicians suggest that disengaged families should make schedules, lists, and organized routines to help restore order and create unity in the chaotic time of medical appointments, cancer treatments, and changing roles within the family (Sherman \& Simonton, 2001). After treatment has ended, clinicians can encourage discussion about the different needs of each family member to maintain family cohesion. Insecure family members often avoid the topic of cancer because it reminds them of the illness-related stressors, leaving the patient feeling neglected as he or she continues to face the long-term effects of cancer (Sherman \& Simonton, 2001). Therapists can address these issues in their work with the families. 
The following vignette from our study of families of breast cancer patients includes the avoidant insecure relational process and demonstrates the cumulative destructive effect of inadequate attachment and caregiving exchanges. Family members may feel overwhelmed and unable to respond to their own emotions and those of the patient when asked about the cancer experience, leaving the patient feeling distressed. HK and her daughter found themselves in this situation after HK was diagnosed with breast cancer:

Patient: So what about you?

Daughter: Mom, don't ask me no questions (nervous laughter).

Patient: You have to say something.... How did you feel when you found out I had breast cancer?

Daughter: I don't have anything to say.

Patient: Hmm?

Daughter: I have nothing to say.

Patient: What did you think? How did you feel?

Daughter I have nothing to say.

(raising

voice

slightly):

Patient: I think your brother should be here, I want to know how he feels.

Daughter: He'd have nothing to say.

Patient: He hasn't talked to the doctors because he hasn't been here. I'd still like to know how he feels. (No response. Long pause). Well, I feel good. So what do you have to say?

Daughter I have nothing to say!

(almost

yelling):
Patient: How did you feel when you found out I had breast cancer?

Daughter: Oh, I was sad (sarcastically).

This mother-daughter relationship exemplifies an insecure avoidant attachment relationship. Constricted communication about cancer prevents the reciprocal exchange of distress and caregiving. The lack of openness about the cancer increases insecurity in the mother-daughter attachment and perpetuates anxiety for both the mother and the daughter. Later in the interaction, the insecure, detached relationship style deteriorates to criticism with the threats of death engendered by cancer:

Patient: It hurts me when I am in bed.

Daughter (rolls her eyes and makes a motion with her head)

Patient: It hurts me when I sleep on it.

Daughter: So buy a new mattress!

Patient: I'll have to put money aside.

Daughter Oh, isn't that a hint!

(rolls eyes

again

and says

sarcastically):

Patient Well, I don't really have a

(long problem, I guess.

pause):

Daughter: Getting back and forth from the doctor's.

Patient: In the wintertime, I'll take the bus until the snow gets on the ground. So it's no problem.

Daughter: Then she'll say, (whines) 'Oh, I took the bus and it was soooo cold.' 
Patient: I'll get some boots so I can walk when it's cold. I have about three more weeks left of my radiation. So it won't be that cold by then. So what else?

Daughter: Nothing, you're well now.

Patient: I'm not well. Y'all have never thought I was sick (nervous laughter). The only comments were, 'Mom, you feel all right?' I wanted [son's name] to say something, he acts like I have something contagious. I don't cook for him no more.

Daughter: He doesn't want you to?

Patient: He doesn't have time, or something.

Daughter: You do cook for him.

Patient: No, I don't. Not lately.

Again, the daughter did not respond to the patient's distress, nor was she communicative about her own stress. When the patient attempted to communicate her feelings about breast cancer, the daughter made sarcastic comments, feigned sympathy, or ignored the patient's concerns, leaving the patient feeling burdened with the need to take care of her problems alone. Early in the interaction, the patient even commented, "I just had to be strong so y'all didn't conk out. So I had to be strong." The patient seems to be saying, "I wish you would comfort me," but she only begins to communicate this feeling to her daughter. As soon as she suggests that the daughter could have been more supportive, she quickly changes the subject to her son out of fear of her daughter's criticism.

Another course is possible for families with insecure attachment styles who face cancer. The uniqueness of need, which arises because of a malignant disease, may illicit new and more productive caregiving responses within the family. A more fruitful pattern of communicating with shared attention and meaning could then arise, feeding back to reinforce a more secure attachment. It is likely that this would occur in situations in which cancer is a novel threat, which can be responded to outside the family's usual patterns of behavior. Insecure families in which an earlier cancer experience has shaped their understanding of themselves, however, would be expected to have amplified fears as a result of the cancer diagnosis.

When disease severity is high, secure relationships may be insufficient to contain the distress. The transformation of relationships over the course of cancer is illustrated by the following family, whose secure attachments were challenged by the patient's illness:

Spouse: I don't know if I've said this to you before, but from the time you were diagnosed, I went through two changes. In the beginning, I wanted to support you. That's what I was trying to do. But afterwards, I went through a time when I truly couldn't accept it. Since the conversation we had 3 months ago, my eyes have opened up. And I hope truthfully that what you're seeing is a lot better than what it was.

Patient Yup.

(nodding

head):

Spouse: I was really unfair.

Patient: Majorly in denial.

Spouse: The bad part about it was, it's like I told mom and I even mentioned it to you. I found solace in beer cans, a glass of wine, a drink, a computer, every place 
except where I needed it and that's in the family. I was afraid to talk about it, I was afraid to face it, but I didn't think I was afraid. I just thought I was being really brave and solid.

This patient's spouse distanced himself from the patient out of fear and shock upon the initial diagnosis of cancer. The demands for emotional involvement were beyond his ability to respond, although he wanted to support the patient. After the patient confronted her spouse about his avoidance of her cancer, however, the communication and mutuality of family process allowed him to fulfill his role as a supportive family member. The couple then reported feeling closer as a result of the cancer threat.

\section{CONCLUSION}

We have described a model of relational development in families when a member has cancer. It is founded on the notion that the threat of cancer is modulated by the security of attachment, such that attachment and caregiving systems are activated in most patients and family members when cancerrelated risks of separation and loss become apparent. The magnitude of threat experienced by each patient and family is the product of its particular high-risk characteristics and varies greatly from family to family. It is within this particular system that the threat of cancer arises for a particular patient.

Wynne's epigenetic model of relational processes, combined with the stage of family development and the phase of cancer, is proposed as a template for distinguishing the type of distortions potentially found in a population of cancer patients and their families. Family therapists suggest that intervention that addresses the specific level of distortion or impasse in family development may help the natural developmental processes in relationships to flourish (Hill, Fonagy, Safier, \& Sargent, 2003). Further application of the epigenetic model of family relational processes is likely to be fruitful for understanding and promoting resilience in the cancer patient and his or her family.

\section{REFERENCES}

Ainsworth, M. D. S., Blehar, M. C., Waters, E., \& Wall, S. (1978). Patterns of attachment: A psychological study of the strange situation. Hillsdale, NJ: Lawrence Erlbaum.

American Cancer Society. (2003). Cancer facts and figures. Retrieved August 25, 2003, from http://www.cancer.org

Arpin, K., Fitch, M., Browne, G. B., \& Corey, P. (1990). Prevalence and correlates of family dysfunction and poor-adjustment to chronic illness in specialty clinics. Journal of Clinical Epidemiology, 43, 373-383.

Bahnson, C. B. (1975). Psychologic and emotional issues in cancer: The psychotherapeutic care of the cancer patient. Seminars in Oncology, 2, 293-309.

Baider, L., Koch, U., Esacson, R., \& Kaplan-DeNour, A. (1998). Prospective study of cancer patients and their spouses: The weakness of marital strength. PsychoOncology, 7, 49-56.

Ben-Zur, H. (2001). Your coping strategy and my distress: Inter-spouse perceptions of coping and adjustment among breast cancer patients and their spouses. Families, Systems, \& Health, 19, 83-94. 
Berman, W. H., \& Sperling, M. B. (1994). The structure and function of adult attachment. In M. B. Sperling \& W. H. Berman (Eds.), Attachment in adults (pp. 1-30). New York: Guilford.

Bloom, J. R., Pendergrass, S. M., \& Burnell, G. M. (1984). Social functioning of women with breast cancer: Validation of a clinical scale. Journal of Psychological Oncology, 2, 93-101.

Bowlby, J. (1969). Attachment \& loss (2nd ed., Vol. 1). New York: Basic Books.

Bowlby, J. (1988). A secure base. New York: Basic Books.

Brown, G., \& Harris, T. (Eds.). (1989). Life events and illness. New York: Guilford.

Burman, B., \& Margolin, G. (1992). Analysis of the association between marital relationships and health problems: An interactional perspective. Psychological Bulletin, 112, 39-63.

Carlson, L. E., Bultz, B. D., Speca, M., \& St.-Pierre, M. (2000). Partners of cancer patients: Part II. Current psychosocial interventions and suggestions for improvements. Journal of Psychosocial Oncology, 18(3), 33-43.

Conger, R., Ge, X., Elder, G., Lorenz, F., \& Simons, R. (1994). Economic stress, coercive family process and developmental problems of adolescents. Child Development, 65, 541-561.

Conger, R., Patterson, G., \& Ge, X. (1995). Parental stress and child adjustment: An across-site replication. Child Development, 66, 80-97.

Derogatis, L. R., Morrow, G. R., Fetting, J., Penman, D., Piasetsky, S., Schmale, A. M., et al. (1983). The prevalence of psychiatric disorders among cancer patients. Journal of the American Medical Association, 249, 751-757.

Edwards, B. K., Howe, H. L., Ries, L. A. G., Thun, M. J., Rosenberg, H. M., Yancik, R., et al. (2002). Annual report to the nation on the status of cancer, 1973-1999, featuring implications of age and aging on the U.S. cancer burden. Cancer, 94, 2766-2792.

Ell, K., Nishimoto, R., Mediansky, L., Mantell, J., \& Hamovitch, M. (1992). Social relations, social support and survival among patients with cancer. Journal of Psychosomatic Research, 36, 531-541.

Ell, K., Nishimoto, R., Morvay, T., Mantell, J., \& Hamovitch, M. (1989). A longitudinal analysis of psychological adaptation among survivors of cancer. Cancer, 63, 406-446.

Ferrell, B., Ervin, K., Smith, S., Marek, T., \& Melancon, C. (2002). Family perspectives of ovarian cancer. Cancer Practice, 10(6), 269-276.

Forsen, A. (1991). Psychological stress as a risk factor for breast cancer. Psychotherapy and Psychosomatics, 55, 176-185.

Giese-Davis, J., Hermanson, K., Koopman, C., Weibel, C., \& Spiegel, D. (2000). Quality of couples' relationship and adjustment to metastatic breast cancer. Journal of Family Psychology, 14(2), 251-266.

Gonzalez, S., Steinglass, P., \& Reiss, D. (1989). Putting the illness in its place: Discussion groups for families with chronic medical illnesses. Family Process, 28, 69-87.

Grassi, L., \& Rosti, G. (1996). Psychosocial morbidity and adjustment to illness among long-term cancer survivors: A six-year-follow-up study. Psychosomatics, $37,523-532$.

Halford, W. K., Scott, J. L., \& Smythe, J. (2000). Couples and coping with cancer: Helping each other through the night. In K. B. Schmaling \& T. G. Sher (Eds.), The psychology of couples and illness: Theory, research, \& practice (pp. 135-170). Washington, DC: American Psychological Association. 
Hill, J., Fonagy, P., Safier, E., \& Sargent, F. (2003). The ecology of attachment in the family. Family Process, 42, 205-221.

Hinde, R. A. (1982). Attachment: Some conceptual and biological issues. In C. M. Parks \& J. Stevenson-Hinde (Eds.), The place of attachment in human behavior (pp. 31-53). New York: Basic Books.

House, J. S., Robbins, C., \& Metzner, H. L. (1982). The association of social relationships and activities with mortality: Prospective evidence from the Tecumseh Community Health Study. American Journal of Epidemiology, 116(1), 123-140.

Kayser, K., Sormanti, M., \& Strainchamps, E. (1999). Women coping with cancer: The influence of relationship factors on psychosocial adjustment. Psychology of Women Quarterly, 23, 725-730.

Kravdel, O. (2001). The impact of marital status on cancer survival. Social Science \& Medicine, 52, 357-368.

Levitt, M., Coffman, S., Guacci-Franco, N., \& Loveless, S. (1994). Attachment relationships and life transitions: An expectancy model. In M. B. Sperling \& W. H. Berman (Eds.), Attachment in adults (pp. 232-235). New York: Guilford.

Levy, S. M., Herberman, R. B., Lippman, M., D’Angelo, T., \& Lee, J. (1991). Immunological and psychosocial predictors of disease recurrence in patients with early stage breast cancer. Behavioral Medicine, 17(2), 67-75.

Lewis, F. M. (1996). The impact of breast cancer on the family: Lessons learned from the children and adolescents. In L. Baider, C. L. Cooper, \& A. KaplanDeNour (Eds.), Cancer and the family (pp. 271-287). New York: John Wiley.

Lewis, F. M., Woods, N. F., Hough, E. E., \& Bensley, L. S. (1989). The family's functioning with chronic illness in the mother: The spouse's perspective. Social Science and Medicine, 29, 1261-1269.

Main, M., \& Hesse, E. (1990). Parents' unresolved traumatic experiences are related to infant disorganized attachment status: Is frightened and/or frightening parental behavior the linking mechanism? In M. Greenberg, D. Cicchetti, \& E. Cummings (Eds.), Attachment in the preschool years (pp. 161-185). Chicago: University of Chicago Press.

Manne, S. L. (1999). Intrusive thoughts and psychological distress among cancer patients: The role of spouse avoidance and criticism. Journal of Consulting and Clinical Psychology, 67, 539-546.

Mikulincer, M., \& Nachshon, O. (1991). Attachment styles and patterns of selfdisclosure. Journal of Personality and Social Psychology, 61, 321-331.

Murphy, M., Goldblatt, P., Thornton-Jones, H., \& Silcocks, P. (1990). Survival among women with cancer of the uterine cervix: Influence of marital status and social class. Journal of Epidemiology \& Community Health, 44(4), 293-296.

Neale, A. V. (1994). Racial and marital status influences on 10 year survival from breast cancer. Journal of Clinical Epidemiology, 47(5), 475-483.

Northouse, L. L., Mood, D., Templin, T., Mellon, S., \& George, T. (2000). Couples' patterns of adjustment to colon cancer. Social Science \& Medicine, 50, 271-284.

O'Mahoney, J. M., \& Carroll, R. A. (1997). The impact of breast cancer and its treatment on marital functioning. Journal of Clinical Psychology in Medical Settings, 4(4), 397-415.

Omne-Ponten, M., Holmberg, L., Bergstrom, R., Sjoden, P., \& Burns, T. (1993). Psychosocial adjustment among husbands of women treated for breast cancer: Mastectomy vs. breast-conserving surgery. European Journal of Cancer, 29A, 1393-1397. 
Ren, X. S. (1997). Marital status and quality of relationships: The impact on health perception. Social Science \& Medicine, 44, 241-249.

Reynolds, P., Boyd, P. T., Blacklow, R. S., Jackson, J. S., Greenberg, R. S., Austin, D. F., et al. (1994). Relationship between social ties and survival in black and white breast cancer patients. Cancer Epidemiology, Biomarkers \& Prevention, 3, 253-259.

Rodrigue, J. R., \& Park, T. L. (1996). General and illness-specific adjustment to cancer: Relationship to marital status and marital functioning. Journal of Psychosomatic Research, 40(1), 29-36.

Rolland, J. S. (1994). Families, illness, and disability: An integrative treatment model. New York: Basic Books.

Sawyer, M. G., Streiner, D. L., Antoniou, G., Toogood, I., \& Rice, M. (1998). Influence of parental and family adjustment on the later psychological adjustment of children treated for cancer. Journal of the American Academy of Child and Adolescent Psychiatry, 37(8), 915-922.

Sherman, A. C., \& Simonton, S. (2001). Coping with cancer in the family. Family Journal: Counseling and Therapy for Couples and Families, 9(2), 193-200.

Shields, C. S., Travis, L. A., \& Rousseau, S. L. (2000). Marital attachment and adjustment in older couples coping with cancer. Aging \& Mental Health, 4, 223-233.

Silberfarb, P. M., Mauer, L. H., \& Crouthamel, C. S. (1980). Psychosocial aspects of neoplastic disease: I. Functional status of breast cancer patients during different treatment regimens. American Journal of Psychiatry, 137(4), 450-455.

Simpson, J., Rholes, W., \& Nelligan, J. (1992). Support seeking and support giving within couples in an anxiety-provoking situation: The role of attachment styles. Journal of Personality and Social Psychology, 62, 434-446.

Singer, M. T., \& Wynne, L. C. (1965). Thought disorder and family relations of schizophrenics: IV. Results and implications. Archives of General Psychiatry, 12, 201-212.

Skerrett, K. (1998). Couple adjustment to the experience of breast cancer. Families, Systems, and Health, 16(3), 281-298.

Spira, M., \& Kenemore, E. (2000). Adolescent daughters of mothers with breast cancer: Impact and implications. Clinical Social Work Journal, 28, 183-195.

Suinn, R. M., \& VandenBos, G. R. (1999). Cancer patients and their families: Readings on disease course, coping, and psychological interventions. Washington, DC: American Psychological Association.

Temoshok, L. (1985). Biopsychosocial studies on cutaneous malignant melanoma: Psychosocial factors associated with prognostic indicators, progression, psychophysiology and tumor-host response. Social Science \& Medicine, 20(8), 833-840.

Trask, P. C., Paterson, A. G., Trask, C. L., Bares, C. B., Birt, J., \& Maan, C. (2003). Parent and adolescent adjustment to pediatric cancer: Associations with coping, social support, and family function. Journal of Pediatric Oncology Nursing, 20(1), 36-47.

Veach, T. A. (1999). Families of adult cancer patients. Journal of Family Psychotherapy, 10(1), 43-60.

Veach, T. A., \& Nicholas, D. R. (1998). Understanding families of adults with cancer: Combining the clinical course of cancer and stages of family development. Journal of Counseling and Development, 76, 144-156. 
Waxler-Morrison, N., Hislop, G. T., Mears, B., \& Kan, L. (1991). Effects of social relationships on survival for women with breast cancer: A prospective study. Social Science \& Medicine, 33, 177-183.

Weber, M. (1964). The theory of social and economic organization (A. M. Henderson \& T. Parsons, Trans.) (pp. 9-10). New York: Free Press. (Original work published 1947)

Weihs, K. L. (2001). Social support network size predicts breast cancer recurrence and mortality, after control for disease severity. Psychosomatic Medicine, 63(1), 153.

Weihs, K. L., Enright, T., \& Simmens, S. (2002). High quality spousal or long-term partner relationships predict time to recurrence of breast cancer, after control for disease severity. Psychosomatic Medicine, 64(1), 107.

Weihs, K. L., Enright, T. M., Simmens, S. J., \& Reiss, D. (2000). Negative affectivity, restriction of emotions and site of metastases predict mortality in recurrent breast cancer. Journal of Psychosomatic Research, 49(1), 59-68.

Weinberger, D. A. (1990). The construct validity of the repressive coping style. In J. L. Singer (Ed.), Repression and dissociation implication for personality theory, psychopathology, and health (pp. 337-386). Chicago: University of Chicago Press.

Weisman, M. D., \& Worden, J. W. (1976). The existential plight in cancer: Significance of the first 100 days. International Journal of Psychiatry in Medicine, 7, 1-15.

Whitbeck, L., Simons, R., Conger, R., Lorenz, F., Huck, S., \& Elder, G. (1991). Family economic hardship, parental support, and adolescent self-esteem. Social Psychology Quarterly, 54, 353-363.

Wynne, L. C. (1970). Communication disorders and the quest for relatedness in families of schizophrenics. American Journal of Psychoanalysis, 30, 100-114.

Wynne, L. C. (1988). An epigenetic model of family processes. In C. J. Falicov (Ed.), Family transitions: Continuity and change over the life cycle (pp. 81-106). New York: Guilford.

Wynne, L. C., \& Wynne, A. R. (1986). The quest for intimacy. Journal of Marital and Family Therapy, 12, 383-394.

Zhu, K., Weiss, N. S., Schwartz, S. M., \& Daling, J. R. (1994). Assessing the relationship between marital status and cancer incidence: Methodologic considerations. Cancer Causes \& Control, 5(1), 83-87. 